\title{
Virtuous Structures
}

\author{
Dirk Vriens $^{1} \cdot$ Jan Achterbergh $^{1} \cdot$ Liesbeth Gulpers $^{1}$
}

Received: 22 July 2015/ Accepted: 8 April 2016/Published online: 19 April 2016

(c) The Author(s) 2016. This article is published with open access at Springerlink.com

\begin{abstract}
To discuss moral behavior in organizations, a growing number of authors turn to a 'virtue ethics' approach. Central to this approach is the so-called moral character of individuals in organizations: a well-developed moral character enables organizational members to deal with the specific moral issues they encounter during their work. If a virtue ethics perspective is seen as relevant, one may ask how organizations can facilitate that their members can exercise and develop their moral character. In this paper, we argue that the way tasks are defined and interlinked (the organization's structure) has a profound influence on "exercising and developing moral character"-it can enhance and frustrate it. In order to show how structures may support organizational members to exercise and develop their moral virtues, the paper first describes what it means to exercise and develop virtues in an organizational setting and what is required for it. Next, the paper sets out to explain how specific values on different structural parameters (formalization, decentralization, specialization, and unit grouping) at different structural levels (micro, macro, and network) relate to exercising virtues in organizations.
\end{abstract}

Dirk Vriens

d.vriens@fm.ru.nl

Jan Achterbergh

j.achterbergh@fm.ru.nl

Liesbeth Gulpers

l.gulpers@fm.ru.nl

1 Faculty of Management Science, Radboud University Nijmegen, P.O. Box 9108, 6500 HK Nijmegen, The Netherlands
Keywords Virtue ethics - Moral character . Organizational structure

\section{Introduction}

For some years now, there has been a growing interest in virtue ethics in organization literature. That is, many scholars have turned to virtue ethics to understand and guide ethical conduct in organizations (see, for instance, the special issues of Organization Studies (2006), Business Ethics Quarterly (2012), Journal of Business Ethics (2013), and Business Ethics: a European Review (2015), which were all devoted to virtue ethics).

What sets virtue ethics apart from other ethical approaches is that it frames ethics in terms of the question "How should I live my life?" instead of "What should I do"? (cf. Weaver 2006, p. 349). Virtue ethics is about living one's life in the best possible way, that is: about striving to develop one's characteristically human capacities into virtues (cf. Achterbergh and Vriens 2010). Part of living one's life in the best possible way is cultivating one's "moral character." A well-developed (virtuous) moral character disposes one to desire, choose, and do the right thing: just acts stem from a just character (cf. Aristotle 1984, 1105b1-10). As Weaver (2006, p. 341) summarizes, the emphasis of virtue ethics is on "[...] virtue or character: what a person is or has rather than merely what a person does."

Translating this to ethical conduct in organizations, virtue ethics inspired business ethicists stress the exercise and development of our moral character ${ }^{1}$ (as part of living a fulfilled life) in an organizational context and rely less on

\footnotetext{
${ }^{1}$ We will refer to moral character as comprising both practical wisdom and moral virtues_-see also Sherman (1989).
} 
mere compliance to rules (see also Hartman 2008). But, if exercising and developing our moral character becomes an issue, it also becomes relevant to understand the organizational conditions fostering it (cf. Weaver 2006, p. 357; Moore and Beadle 2006).

In this paper, we want to highlight one particular organizational condition: the way jobs are defined, related, and coordinated. With Mintzberg (1983) we refer to this condition as the organizational structure. We believe that organizational structures make a difference with respect to the prospect of exercising and developing virtues in organizations (a belief we share with others-e.g., MacIntyre 1985, Jos 1988; Luban et al. 1992; Moore 2005a, b; Moore and Beadle 2006; Breen 2012; Beadle and Knight 2012; Weaver 2006). In fact, as some authors argue, some structures frustrate the exercise and development of our moral character (typically bureaucracies, cf. MacIntyre 1985; or Tayloristic, "technicist" structures, cf. Breen 2007, 2012) while other structures may enable us to exercise and develop our moral character (as, for instance, discussed in Achterbergh and Vriens 2010; Moore and Beadle 2006; Beadle and Knight 2012; Schwartz and Sharpe 2010; Schwartz 2011; Breen 2012).

In this paper, we focus on these enabling, supportive structural conditions [an endeavor, also called for by Hartman (2008), Beadle and Knight (2012) and Weaver (2006)] in a systematic way. More specifically, we follow scholars on organizational structures (e.g., Mintzberg 1983; de Sitter 1994) to specify supportive structural conditions for exercising and developing virtues at two "structural" organizational levels (at the micro-level of individual jobs, and at the macro-level of the organization) and at the level of organizational networks. To this purpose, we use four structural parameters: unit-grouping, decentralization, job-specialization, and formalization. In doing so, we set out to contribute to the current discussion about "virtuous structures" by providing a detailed (organizational theoretic) description of the structural characteristics enabling virtuous behavior in (networks of) organizations.

The main strategy to realize our goal is that we identify (1) requirements for exercising and developing moral character in organizations, and (2) structural characteristics (at two organizational levels and at the network level) contributing to these requirements. Thus, we characterize supportive, "virtuous" structures. But, it should be clear from the outset that structures, however much they are geared at the requirements for exercising and developing virtues, they do not by themselves guarantee or determine virtuous behavior. Our thesis is that structural conditions increase the possibility of exercising and developing moral character (a thesis shared by others-as we will discuss below) by their contribution to its requirements.
The paper is organized as follows. In the next section, we discuss the importance of a systematic treatment of structural conditions for exercising and developing virtues. In "What is Required for Exercising and Developing Virtues in Organizations?" section, we discuss what it means to exercise and develop virtues in organizations and identify three requirements for the prospect of doing so. In "Virtuous Structures at the Enterprise Level" and "Virtuous Structures at the Job Level" sections, we will discuss supportive structural conditions at two organizational levels: at the "enterprise" level ("Virtuous Structures at the Enterprise Level" section), and at the level of individual jobs ("Virtuous Structures at the Job Level" section). In "Virtuous Structures and Networks" section, we treat "virtuous networks" by going into the structural characteristics of networks of organizations. Finally, the last section summarizes and reflects on our findings.

\section{The Importance of a Systematic Treatment of Organizational Structures for Virtuous Action in Organizations}

In this paper, we want to offer a systematic treatment of how organizational structures can support exercising and developing moral character in organizations. As virtue ethics has it, developing our moral character is part of living a fulfilled life as a human being; it is part of our self-realization. And so, as we spend much of our lives in an organizational setting, one could say that making sure that organizational structures help us to develop our moral character is an important endeavor. Moreover, as members of organizations, we encounter all kinds of situations having a moral purport, calling for the exercise of our practical wisdom and moral virtues so that we desire, choose and do the right thing for the right reasons. Organizational structures should support-and not hinder-us in this exercise. On these views, it may even be seen as a moral obligation to build structures that support the exercise and development of moral character as such structures help organizational members to live a fulfilled life and at the same time enable them to engage in morally sound action (although, of course, supportive structures do not guarantee just behavior). So, in the first place, the search for structures nurturing moral character is relevant in the context of improving our human condition. (cf. Breen 2007, 2012; Schwartz and Sharpe 2010; for similar arguments directly tied to structures and virtue ethics; or Schwartz 1982; Walsh 1994; Michaelson 2011; Michaelson et al. 2014, for similar arguments in the context of meaningful work).

At the same time, the current treatment of structures for supporting virtues still seems to be underdeveloped. That is, in our view, the attention paid to the role of structures is 
somewhat biased; in that it often focuses on the frustrating effect of structures instead of their enhancing effect. Moreover, studies focusing on the supportive effect of structures might, in our view, still be improved upon.

Authors, such as MacIntyre (1985), Jos (1988), Luban et al. (1992), and Schwartz and Sharpe (2010), mainly describe the frustrating effect of structures. For instance, MacIntyre (1985) ferociously attacks bureaucracies as structures in which it is very difficult to exercise and develop virtues. As Jos (1988) and MacIntyre (1985) argue, we cannot expect much from members of bureaucracies, morally speaking, because they should "parcel out their soul," "eliminate all personal motivations," and "develop a habit of painstaking obedience" in order to efficiently carry out "the tasks that are entrusted to them by those above them in the hierarchy" (Jos 1988: 329-330). Bureaucrats aren't supposed to exercise their moral character in the context of their work; they should see themselves " $[\ldots]$ as morally neutral characters whose skills enable them to devise the most efficient means of achieving whatever end is proposed" (MacIntyre 1985, p. 74).

Besides those expressing a negative influence of structures on virtuous behavior, there are several authors who acknowledge the need to understand the positive role of structures in supporting the exercise of virtues in organizations. For example, Weaver (2006) acknowledges the potentially positive influence of structures (particularly related to "job-design and social network structure," p. 359) and calls for more research. Likewise, Moore (2005a, b), Beadle and Knight (2012), and Breen (2007, 2012) explore the conditioning role of structures for exercising virtues (given their MacIntyrian notion of virtue ethics). Moore (2005a, p. 251), for example, suggests that virtue-supportive jobs require "team-building and empowerment" as well as "more information and power to make decisions" so that "employees are able to exercise self-control and self-direction." In (2005b), Moore adds an appropriate "power-balanced structure" as another structural requirement to make his MacIntyrian virtue-ethics approach work. Beadle and Knight (2012) formulate a MacIntyre-based, virtue-ethics idea of 'meaningful jobs' and argue that particular job features and characteristics as formulated in the area of individual job design may foster the exercise of virtues. Designing 'virtuous' jobs entails "creating complete units of work," "increasing the range and difficulty of tasks" and "improving feedback" (p. 439). Beadle and Knight also call for more research into job redesign in the context of virtue ethics, so that we can come to understand how to "[...] develop the types of workplaces in which virtues are cultivated and people flourish" (p. 446). Likewise, Breen $(2007,2012)$ introduces the idea of "phronetic production" in which the work organization comprises "complex and coherent" tasks
(Breen 2012, p. 621), allowing employees to have "an overview of the entire work" (p. 612) and in which "[...] there is no categorical distinction between those who lead and those who follow" (p. 621). In addition, Bernacchio and Couch (2015) argue that structures should enable participatory governance so as to enable organizational members to align the goals of the organization to overarching goods of the community. And, starting from a more Aristotelian notion of virtues, Schwartz (2011) argues that organizational structures should be less formalized so as to nurture "practical wisdom."

These suggestions for structural conditions enabling virtuous behavior in organizations fit Moore and Beadle's (2006) general description of requirements for virtuous business organizations. Virtuous organizations require, in their view, preconditions at three levels. They require (1) virtuous agents, (2) a conducive mode of institutionalization, and (3) a conducive environment. The supportive structural conditions as discussed by the above authors can be regarded as attempts to describe parts of the conducive mode of institutionalization enabling the virtuous behavior of organizational agents.

So, prior research does treat enabling structural conditions for exercising and developing virtues. However, we feel that this treatment can be extended in several ways so as to increase our understanding of supportive structures. In particular, we think that the organization design framework featuring four (related) structural parameters at three different levels, presented in this paper, can help gain a more in-depth understanding of the effect of structures on virtuousness. We argue that by means of this framework we can further our understanding of supportive structures in the following ways. First, by making explicit that at least four structural parameters are relevant for developing and exercising virtues, we propose to add the parameter "unit grouping" - how activities are grouped into organizational units - to the parameters already (implicitly) discussed in literature. Second, we employ ideas from organization design theory to provide a more detailed framework for understanding and designing structures enhancing virtuous behavior. The framework makes more explicit that and how structural parameters are involved in designing tasks enhancing virtuous behavior. Third, the framework can help understand the interrelations between and the joint effect of structural parameters on virtuous behavior. It can help us to see, for instance, that structures at the macrolevel of organizational structures condition the design of individual jobs in which virtues can be exercised and developed. Or, it can help us to see that the positive effect of parameters on virtuousness can be enhanced or frustrated by the effect of another parameter. Fourth, the framework adds to our understanding of supportive structures by including three different levels: the macro-level, 
the micro-level of individual work, and the level of networks of organizations. This is an addition because the network-level has received virtually no attention in the literature. In all, we set out to extend our understanding of the supportive influence of organizational structures on exercising and developing virtues by a more detailed treatment of all relevant structural parameters (and their relations), at a macro- and micro-level of organizations, and at the level of a network of organizations.

Our search for virtuous structures in this way also fits the model of preconditions for virtuous organizations given by Moore and Beadle (2006). By means of our framework of structural parameters at three different levels, we hope to extend our knowledge of (1) conducive institutionalizations-by means of understanding supportive structures at the two organizational levels, and (2) conducive environments-by treating supportive structures of inter-organizational networks.

\section{What is Required for Exercising and Developing Virtues in Organizations?}

In order to discuss organizational structures supporting exercising and developing virtues, we need to explain what it means to do so in organizations. Moreover, we need to describe what this requires in organizations. These requirements will serve as an anchor for discussing the supportive "virtuous" structures we are after.

\section{Exercising and Developing Virtues}

In this paper, we assume that the reader is familiar with an Aristotelian account of exercising and developing virtues. That, is, we assume the following basic virtue ethics notions from the Ethica Nicomachea. A key notion from Aristotelian virtue ethics is eudaimonia, living a fulfilled life as a human being. Living a fulfilled life is aimed at perfecting our most characteristically human capacities (the capacity for reason and-in a derivative sense-for desire) into virtues. This makes virtue ethics a teleological approach, as it sees perfecting our capacities into virtues as the goal of a human life. Two virtues are particularly relevant in discussing ethical conduct: moral virtues (which dispose us to desire the right thing - 'the mean'-in specific situations with respect to emotional and desiderative dimensions, and which disposes us to desire the right thing for its own sake) and practical wisdom (which is about knowing what it means to life a fulfilled life in general, and which enables us to construct, choose and act in an "appropriate" (morally good) way in particular circumstances (realizing our desire to life a fulfilled life hereand-now). With Sherman (1989), we will say that practical wisdom and moral virtues constitute our "moral character" and come together in making choices about how to live a fulfilled life in particular circumstances, guiding our everyday moral life by providing us with a desire to do the right thing and the capacity to act in accordance with this desire.

We exercise the virtues of our moral character to deal with everyday moral issues in particular situations. This means that (a) we see that a particular situation is morally relevant, (b) we see the relevant related moral dimensions, (c) we see the appropriate mean on these moral dimensions, (d) we desire to act in a way that hits this mean and desire this for its own sake, (e) we are able to select an act (by means of deliberate or intuitive construction and judgment) that fits the desire, given the particulars of the situation, and finally (f) we act accordingly because it is the right thing to do. Moreover, based on our actions we may receive immediate feedback (e.g., in terms of the emotions displayed or reactions given by those who experience the results of our actions) and use that to adjust our ideas about what is morally relevant and desirable, and about the appropriateness of our action, and, if the situation allows it, adjust our actions-see Fig. 1 for an overview.

Exercising virtues also entails that we can reflect (both individually and with others) on how we framed and dealt with a moral issue in a particular situation, on how others reacted to that, and that we use this reflection to further refine our moral character (see also Fig. 1). In this way, exercising virtues is embedded in an experiential (moral) learning cycle by means of which we further develop (shape and perfect) our moral virtues and practical wisdom. So, based on our moral character, we deal with moral issues, and by exercising our moral character we further develop it (see also right hand side of Fig. 1).

\section{Exercising and Developing Our Moral Character as Members of Organizations}

As virtue ethics is about perfecting our moral character so that it disposes us to desire, choose, and do the right thing for the right reasons, we might ask what it is that makes our actions, performed as organizational members 'right' actions-actions we may desire for their own sake, in the context of living a fulfilled life.

To answer this question, we may start off from Solomon's treatment of virtues in organizations who sees individuals as members " $[. .$.$] of (at least) two communities$ at once-the organizational community and the larger surrounding (global) community" (Solomon 2004: 1023), and hence our virtuousness refers to being a member of both communities. As he writes: "What is worth defending in business is the sense of virtue that stresses cooperative joint effort and concern for consumers and colleagues 
Fig. 1 Exercising and developing our virtues

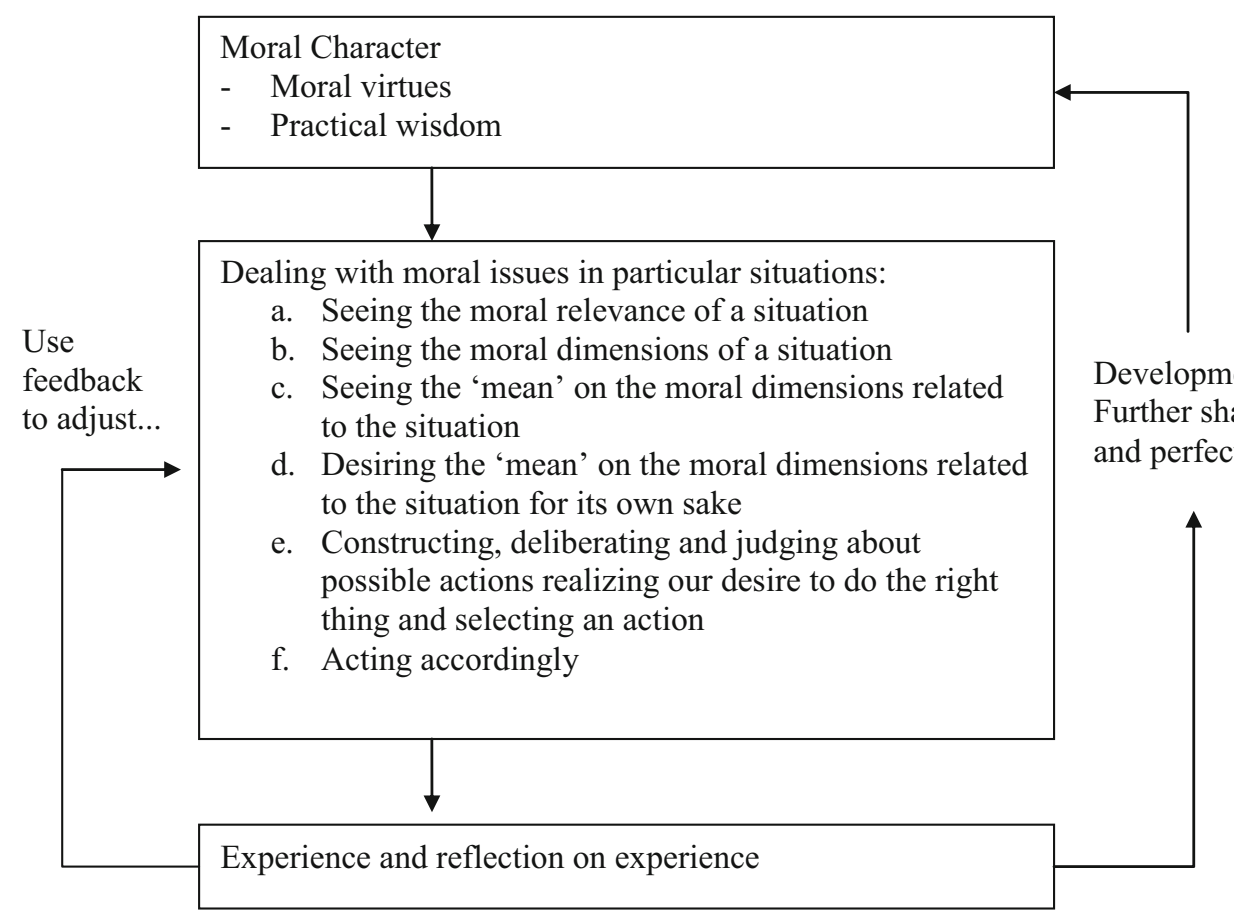

alike" (2004: 1025). Exercising and developing virtues in organizations, then, relates to 'doing the right thing' (1) with respect to other members of the organizational community, and (2) with respect to the organization's environment - the society an organization contributes to.

As a "virtuous" member of an organizational community, we exercise and develop our moral character with respect to others in the organization. This can be done in situations that are not directly tied to our job-related activities (e.g., comforting a grieving colleague). Helping others in distress is something that virtuous actors would normally desire and do for its own sake. If these others are (accidentally) other organizational members, virtuous members of organizations would of course desire to help them as well. However, such not directly job-related behavior falls beyond the scope of this paper.

Exercising and developing our moral character with respect to others in the organization can also be done as part of our job. For instance, if a virtuous actor sees that certain job-related actions may cause others down the line to do extra work, the actor may acknowledge this as an unwanted effect and may try to prevent it. Or, if a manager, responsible for designing working conditions sees that certain choices he made have led to degrading work, heas a virtuous manager (see also Moore 2008; Beabout 2012, for the possibility of virtuous management) - may see that this is an unwanted effect and may try to redesign these conditions
So, as a virtuous member of an organizational community I desire to do the right thing for other members of that community. I should desire this for its own sake, and given my practical wisdom (and skill), I should devise and implement actions realizing this desire.

As Solomon argued, organizational members are also members of a larger community (society) and exercising and developing our moral character as organizational members should also relate to this larger community. An organization may contribute to this larger community by means of its (intended or unintended) output (e.g., by means of its products, services, diminishing waste, wages, employment, etc.). As some authors put it: organizations may contribute to "the good of a community" they are part of (cf. Achterbergh and Vriens 2010; Breen 2012; Moore 2012; Bernacchio and Couch 2015; Sison and Fontrodona 2012). Achterbergh and Vriens (2010) and Sison and Fontrodona (2012), for instance, explicitly discuss this contribution in terms of the organization contribution to the flourishing of organizational members. Now, as an organizational member I contribute to the organization's output (and hence possibly to the communal good) by means of my job-related activities. Virtuously exercising and developing my moral character in this context means that I am genuinely concerned with the well-being of the societal members the organization's output relates to (either directly-e.g., consumers, clients, patients, or indirectlye.g., those affected by pollution, or unemployment). That 
is, I care for this well-being for its own sake and desire that the output of the organization contributes to it. Moreover, it entails devising and implementing job-related actions contributing to this desired output. In order to be virtuous, then, organizational members should have an idea of the output of the organization and assess whether it does contribute to the well-being of societal members. Moreover, they should have an idea of their own contribution to the desired output and devise and implement job-related actions so as to deliver their contribution to it. (This may also entail changing the output itself, if it is assessed to be undesired).

Our description of exercising and developing virtues as part of organizational member's jobs-i.e., with respect to other members of the organization and to the organization's environment (see also Solomon 1992; 2004), relies heavily on Aristotelean ethics and politics (which both are about Eudaimonia). A similar concern with others in the organization and the wider community can also be found in neo-Aristotelean (MacIntyrean) thought, in which exercising virtues relates to both the so-called practice which an institution (e.g., the organization) houses and the wider community (cf. MacIntyre 1999; Moore 2005a; Moore and Beadle 2006; Beadle and Knight 2012).

An important implication of this line of thought is that all that we do in organizations can be considered from a "technical" and from a "moral" point of view. From a technical point of view, we can assess whether an action is effective to realize a particular goal. From a moral perspective, we can assess whether an action contributes to the well-being of organizational or societal members and can be desired for its own sake.

It is also important to note that contributing to the wellbeing of societal members in this reasoning is not maximizing a utilitarian "greatest amount of good for the greatest number." Rather, it should be understood as contributing to conditions enabling societal members to live a fulfilled life, because this is the right thing to do (cf. Sison and Fontrodona 2012). The notion of "contributing to the well-being of societal members" also relates to the capabilities approach (cf. Nussbaum and Sen 1993; Nussbaum 2011; Bertland 2009) which states that societies should secure the necessary "capabilities" for human development. And, as part of society, organizations can contribute to creating these capabilities (cf. Bertland 2009, for a discussion on the relation between virtue ethics and the capabilities approach). With van Tongeren (2004, p. 12), it can be argued that based on virtue ethics one can think of "just" institutions (or a "just" society) as those institutions (or that society) that stimulate people to exercise and develop virtues. Similar ideas are put forward by: Achterbergh and Vriens 2010; Koehn 1998; Collins 1987; Solomon 1992, 2003, 2004; Newton 1992; Mintz 1996.

\section{Requirements for Virtuous Structures}

In this section, we discuss three structural requirements that should be met so as to enable organizational members to exercise and develop their moral character:

1. structures should provide a "teleological context"i.e., they should enable organizational members to see and reflect on the goals and output of the organization in relation to its societal contribution. Moreover, they should be able to see how tasks (at different organizational levels) are connected to this contribution;

2. structures should provide a "deliberative context" enabling organizational members to (learn to) act virtuously in specific circumstances-in such a way that they can actually realize their fulfilled life as an organizational member in the best possible way. This entails that structures should help organizational members to see the consequences of their actions, to provide them with requisite operational variety and regulatory potential, and to grant them the opportunity to learn;

3. structures should provide the "social context" required for reflective discussions about the societal contribution of the organization and for deliberating about actual job-related actions needed to realize this contribution.

\section{Requirement 1: Teleological Context}

A first requirement for enhancing exercising and developing virtues as organizational members is that structures should provide members with a 'teleological context' - in which they can see and reflect on how the organization's actual goals and output are related to its societal contribution. In addition, to be able to serve as an anchor for their own moral organizational behavior, structures should enable members to see how their own tasks are connected to organizational goals and output. This entails that structures at each organizational level should enable members to be 'in touch' with the goals and the output of the organization. Based on such knowledge, we can assess the possible consequences of our own organizational task to society. That is, based on this knowledge we can, for instance, judge whether we contribute to just or doubtful goals, whether our tasks contribute to unintended harmful side-effects, or whether our tasks may endanger the production of (in itself valuable) output. 'Keeping in touch' with organizational goals and output is relevant for exercising and developing virtues, for, if organizational goals aren't clear to organizational members, they don't know what they are contributing to-and they necessarily remain clueless about whether their contribution makes a 
difference to society. In fact, they may be contributing to particularly evil ends - a point vividly made by MacIntyre (1985) and Bauman (1989). The idea of keeping in touch with goals is also raised by other authors on virtues in organizations. For instance, by Moore (2005b: 675) who argues that "[...] the practice-institution combination must reflect on its own telos" to make sure that its purpose is a “just purpose." Bernacchio and Couch (2015) also raise this issue in their discussion of "governance modes" securing the alignment of organizational goals to the good of the community. Being in touch with goals is also a requirement for making sure that the 'bureaucratic self' does not take control over our moral life, as MacIntyre (1985) (and before him Weber) has it, because if we know the goals we are contributing to, we can question them.

A similar reasoning applies to keeping in touch with the organizational output. If members have no knowledge of the overall performance of the organization, they are unable to relate their own tasks to it, let alone that they can judge whether their tasks contribute to something valuable for society.

So, to support virtuous behavior in organizations, structures should provide what we call a "teleological context" - which enables organizational members to see how the actual goals and output of the organizations are related to the organizational contribution to society and to see how their tasks relate to this contribution.

\section{Requirement 2: Deliberative Context}

Structures should enable organizational members to exercise and develop their moral character in specific circumstances so as to enable them to come up with actions that actually realize living a fulfilled life as an organizational member in the best possible way. So, where the teleological context provides an awareness of the societal contribution, goals and output of the organization and how tasks are connected to them, this second requirement should enable the actual context-specific deliberation and action needed for virtuous behavior. To this end, it is required that structures enable organizational members to (A) see the (possible and actual) moral consequences of their (potential and actual) actions, and (B) provide them with the opportunity to devise and implement virtuous actions so as to be able to bring about the desired moral consequences..

Seeing the Consequences of Actions Exercising and developing virtues in organizations implies that we can see the moral consequences of our job-related activities, i.e., whether they do indeed have the intended, desired effect (and not other, unintended, undesired effects). Without an awareness of the consequences of our job-related activities, we cannot assess their possible harm or benefit (see also
Luban et al. 1992; Grant 2007). The less we know about the consequences of our actions, the harder it is to exercise our practical wisdom and think about appropriate alternatives. Exercising our virtues entails that we should be aware of the possible consequences of our actions for other organizational members and know how our job-related activities contribute to the (intended and unintended) output of the organization. Seeing the actual consequences of our moral actions is required for monitoring their appropriateness in a specific situation and for adjusting them (if necessary). It is also a prerequisite for further developing our moral character, for this occurs by reflecting on these moral consequences. If we do something with the intention to do the right thing, and we cannot see the consequences of this action in terms of how it influences the (fulfilled) life of those affected, it becomes difficult to know whether our intention did indeed lead to the desired moral effect in this particular situation. And, as a result, it becomes impossible to reflect on these actions (and on the desire serving as a background for it) and adjust either desire or moral action to guide us in similar future situations. Moral learning, then, requires knowledge of the consequences of our actions (see also Weaver 2006, for a similar argument with respect to moral identity).

In organizations, this means that, ideally, one has an overview over the production process one is part of; one knows how this process is broken down into parts and how they are connected-so as to be able to trace possible and actual consequences of one's actions and know their impact to all parts of this network - and beyond (this is related to Grant's idea (2007) of 'relational jobs' in which workers know the impact of their job on beneficiaries and have contact with them, to Beadle and Knight's (2012) plea for "complete units of work," or to Breen's (2012) "phronetic work"-see earlier).

In all, exercising and developing our virtues in organizations is supported by structures that allow us to see the possible and actual internal and external moral consequences of our organizational actions.

Devising and Implementing Virtuous Actions Besides knowing the moral consequences of one's (actual and potential) actions, one should also be enabled to influence these consequences. Put differently, one should be enabled to grasp the moral essentials of a particular job-related context, to formulate possible moral actions, to deliberate and judge with respect to them, to select and carry out fitting actions, monitor their results and adjust the actions if required. Moreover, exercising and developing virtues entails that organizational members should reflect on their actions and further refine their moral character. This requires, in our view, that jobs should be sufficiently rich, i.e., they should include both enough 'operational variety,' 
'cohesion,' and 'regulatory potential.' Based on operational variety and regulatory potential organizational members can influence the moral consequences of their job-related activities.

Our jobs need a certain degree of operational variety and cohesion, otherwise exercising moral character would lack efficacy. That is, if my job only consists of a few very small short-cycled activities, I may simply not have the time for moral decision making, and action and learning. And, even if I had the time, and I realized that certain moral actions might be required, it may very well be that based on the few short-cycled activities that I am supposed to carry out, I would not be able to engage in moral action as part of my $j o b$. In a similar vein, I may see that my job contributes to a wrong end-but given the low variety of my short-cycled activities I may not be able to do anything about it. What kind of sustainable contribution can I make if I only sort out flawed material on a fast moving conveyer-belt? How can I change my contribution in the desired direction if I lack the operational variety for doing so? In this respect, Breen (2012) states that jobs should contain a "complex set of interrelated tasks $[\ldots]$ that $[\ldots$ can...] be combined in a effective way" (p. 621). Such jobs are coherent, in that they are meaningfully and logically tied to the output.

A similar line of reasoning applies to moral development. If my job doesn't allow me to perform activities beyond a narrowly defined set of activities, I may never learn about the appropriateness of other possibilities to deal with certain moral issues. Experiential learning seems to imply a certain operational variety so as to be able to experiment and learn about other ways of dealing with problems (see also Kolb 1984; Weaver 2006).

Besides operational variety, we also need the regulatory potential to propose certain actions that are morally required and the discretionary power to implement them (see also Beadle and Knight 2012; Moore 2005a; Breen 2012 who argue for job-related decision power to enhance virtuous action). For instance, we may find out that a particular supplier uses human resources in a way that is suspicious-e.g., by exploiting workers in developing countries). If we want to do something about it, we should have the discretionary power to either put pressure on this supplier to change things, or to find other suppliers and make new arrangements with them-or at least to put the matter on the agenda. If one doesn't allow for the delegation of regulatory potential to the relevant levels, one cannot really make moral guidance an issue, for it may lead to the situation in which one may see that changes are needed but that their realization depends on higher level managerial action.

Other authors have also hinted at the necessity of these operational variety and regulatory potential for virtuous behavior (e.g., Moore 2005a, b; Weaver 2006; Breen 2012;
Beadle and Knight 2012). Beadle and Knight, for instance (p. 439) argue that "increasing the range and difficulty of tasks and creating complete units of work" (operational variety) fits their MacIntyrean understanding of exercising virtues. They also argue for more regulatory potential "as workers $[\ldots]$ are brought into decision-making and negotiation about the purpose and organization [...]" so that they can "pursue their own standards of excellence" (p. 439).

\section{Requirement 3: Social Context}

The last requirement for 'virtuous structures' that we want to stress is that they should provide members of organizations with the opportunity to be an active part of a social network. This relates to Solomon's ideas of the role of 'organizations as communities' in the context of virtue ethics (e.g., Solomon 2004). As virtue ethics suggests, we apply and develop our moral character as social beings. The (organizational and larger societal) community we are member of, serves as a background for our moral awareness, and our moral deliberation, judgment and reflection as we deal with moral issues. And, at the same time, the communities we are part of provide the network of relevant others required for social deliberation and reflection. This social network also provides a 'communal' background in which moral virtues and practical wisdom may develop. Communication with other members of the organization may fine-tune our job-related moral virtues and it may help us to improve our practical wisdom. It is by means of interaction and communication that we experience (most of) the results of our moral actions, and communication helps us to reflect socially on our moral values, actions and their consequences. Being connected with others, then, is a requirement for moral action and development of our moral character in organizations (cf. Koehn 1998; Solomon 2004; Weaver 2006). The social embeddedness is also apparent in Moore's (2005b) and Moore and Beadle's (2006) suggestion that one should engage in a "critical dialogue" or in Beabout's (2012) argument that virtuousness requires "reasoning with others about the worthiness of ends" (p. 426). MacIntyre (1999) concludes that a social setting is crucial for moral agency as " $[\ldots]$ accountability to others, participation in critical practical enquiry and acknowledgement of the individuality both of others and of oneself" (p. 317) depend on it.

Ideally, this social context includes internal and external stakeholders. This point is also explicitly made by Moore (2012), who writes that a "[...] contribution to the overriding good of the community [...requires...] a continuing debate within the organization, and ideally between the organization and the community or communities of which it is a part" (p. 309). In all, structures should provide jobs 
that are sufficiently socially connected to each other and to the relevant environment (cf. Achterbergh and Vriens 2010).

\section{Virtuous Structures, Parameters and Levels}

In this paper, we define virtuous structures as organizational structures that can realize the teleological, deliberative, and social context requirement and in this way enable organizational members to exercise and develop their moral character. An organizational structure is defined as the way in which the organization's overall task is decomposed into subtasks and how these subtasks are coordinated (cf. Mintzberg 1983).

To describe and design organizational structures, socalled 'structural parameters' have been developed. Although different authors distinguish different parameters (e.g., Pugh et al. 1968; Mintzberg 1983; Galbraith 1977; de Sitter 1994; de Sitter and den Hertog 1997), most of them agree on four basic parameters: unit grouping, decentralization, job specialization, and formalization. Each of these parameters can have different 'values.' Dependent on the values of its parameters, the structural lay-out of an organization has particular characteristics, enabling or disabling organizational members to act in particular ways. For instance, if the value of the structural parameter 'decentralization' is 'low,' organizational members in the operating core of the organization have little decision authority regarding the regulation of their own work (Pierce and Delbecq 1977). This does not help them to learn to solve job-related problems by themselves. Structural parameters can be used to describe virtuous structures. In this case, the question is, "Which value should the structural parameters have in order to provide organizational members with the teleological, deliberative, and social context to be able to exercise and develop their moral character?"

Organizational structures can be described and designed at different levels of an organization. In this paper, we distinguish two levels.

The first is what Nadler and Tushman (1997) call the 'enterprise level.' At this level, one finds the units (business units, production flows, departments, teams, groups) that make up the organization. Note that the enterprise level may have a complex structure, for instance, it may consists of business units that comprise departments that, in turn, comprise teams. At the enterprise level, the parameters 'unit grouping' and 'decentralization' are of particular importance. In "Virtuous Structures at the Enterprise Level" section, we use these parameters to describe virtuous structures at the enterprise level.

The second level is that of individual workers and their jobs. We call this level the 'job level.' The relevant parameters at this level are 'job specialization' and 'formalization.' In "Virtuous Structures at the Job Level" section, we use these parameters to discuss virtuous structures at the job level.

\section{Virtuous Structures at the Enterprise Level}

In this section, 'virtuous structures' at the enterprise level are at issue. To this purpose, we ask ourselves what the values of the relevant parameters at the enterprise levelunit grouping and decentralization-should be in order to increase the probability of the realization of the teleological, deliberative, and social context requirement. Structures with these parameter values are the virtuous structures at the enterprise level we are looking for. To discuss these virtuous structures, we start in "Enterprise Level: Unit Grouping" section with the parameter unit grouping. "Enterprise Level: Decentralization" section deals with the parameter decentralization.

\section{Enterprise Level: Unit Grouping}

To discuss virtuous unit grouping at the enterprise level of organizations, we first define this parameter and describe its extreme values ("The Parameter Unit Grouping" section). Then, in "Virtuous Unit Grouping" section, we describe virtuous unit grouping in theory. "Virtuous Unit Grouping: A Practical Example" section discusses a practical application of virtuous unit grouping in a home care organization.

\section{The Parameter Unit Grouping}

The parameter 'unit grouping' refers to the way production activities are grouped into organizational units, e.g., business units, departments, teams (cf. de Sitter 1994; de Sitter and den Hertog 1997; Mintzberg 1983). The parameter unit grouping can have two extreme values: 'high' and 'low' functional concentration (cf. de Sitter 1994; de Sitter and den Hertog 1997).

In the extreme case of high functional concentration, all order types are potentially coupled to all operational subsystems or units (cf. de Sitter and den Hertog 1997, p. 507). An example of high functional concentration would be an organization producing two types of doors and three types of windows (five order types in total). Moreover, in this organization all sawing activities are grouped into a 'sawing department,' all sanding activities into a 'sanding department,' all assembly activities into a 'assembly department,' and all finishing activities into a 'finishing department.' In this organization, each department processes all order types, i.e., all order types are potentially coupled to each of the units (see Fig. 2). 


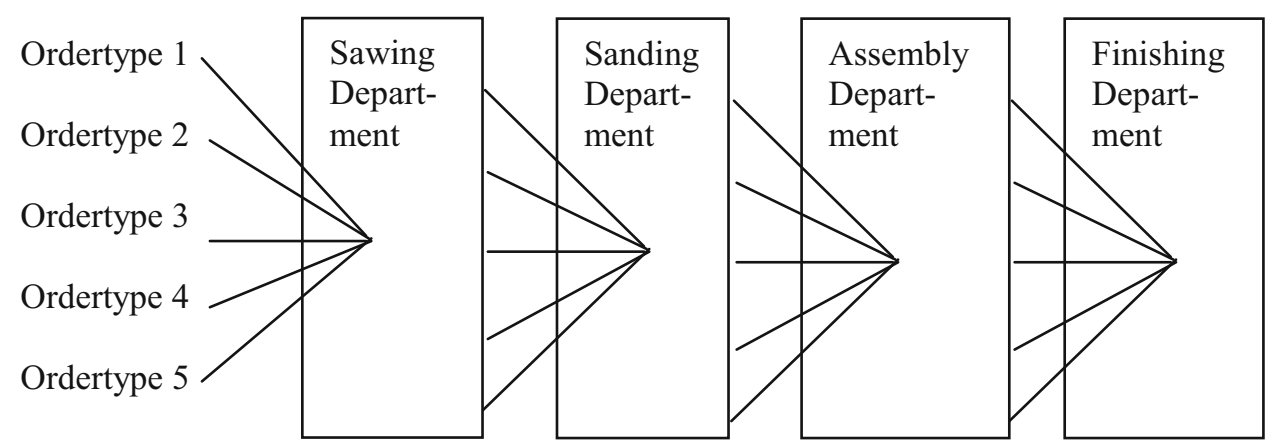

Fig. 2 Example functional concentration

In the extreme case of low functional concentration, each order type is produced by its own corresponding unit (cf. de Sitter and den Hertog 1997, p. 507). In this case, each unit should have its 'own' personnel and equipment in order to produce 'its' order type. In this way, relatively independent parallel production flows come into existence. In the literature, low functional concentration is also called 'flow production' (de Sitter and den Hertog 1997; Womack et al. 1990; Seddon 2008).

In the example, low functional concentration would mean that five units are formed, each with its own sawing, sanding, assembly, and finishing activities, personnel, and equipment. In this case, not all order types are coupled to all units (see Fig. 3).

Of course, high and low functional concentration as portrayed in the example are extreme values of the parameter unit grouping. An example of an intermediate degree of functional concentration would be two flows: one dedicated to the production of doors, the other to the production of windows.

Note that the idea of high and low functional concentration is also reflected in Mintzberg's distinction between 'function' and 'market' based unit grouping (Mintzberg 1983, pp. 53-54). Moreover, unit grouping has also been discussed along these lines by Walker and Lorsh 1968; Anand and Daft 2007.

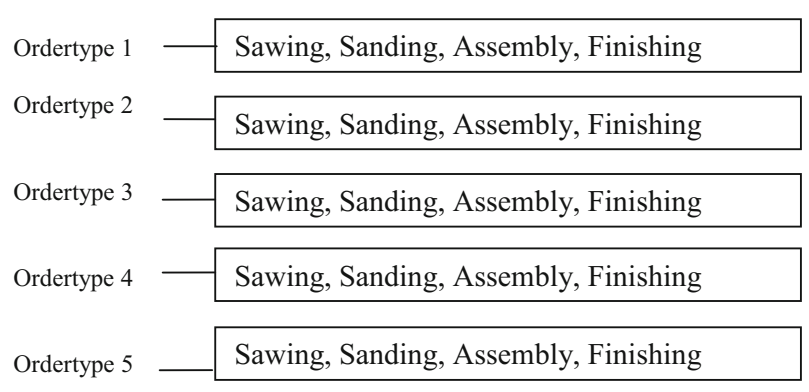

Fig. 3 Example flow production

\section{Virtuous Unit Grouping}

The grouping of activities into units at the enterprise level directly affects the creation of a teleological and social context (requirements 1 and 3). Moreover, it provides conditions for the design of individual jobs enabling the exercise and development of moral character (requirement 2).

From the two extreme values of unit grouping-high and low functional concentration-low functional concentration (flow production) seems to provide the best conditions for the realization of the three requirements.

Low functional concentration at the enterprise level of an organization means that organizational units at this level produce a subset of all the order types produced by that organization. For production purposes, each unit is a production flow that has its 'own' goals, input, throughput, output, personnel, and equipment. This production flow provides a basis for organizational members to be in touch with 'their' flow's impact on and contribution to society. It provides a basis for the teleological context needed to develop and apply work-related virtues. Moreover, this type of grouping allows for 'flow-related' communication, enabling discussion about the unit's 'telos' in relation to that of the organization. Finally, flow-related production allows organizational members to assess the appropriateness of their activities in relation of the organization's 'telos.'

If functional concentration is high, all units are potentially connected to all order types. Particularly if the number of different order types is high, organizational members working for these units tend to lose sight of both the unit's and the organization's contribution to society (de Sitter 1994; de Sitter and den Hertog 1997). Workers concentrate on the function of their unit (e.g., 'sawing' or 'finishing'), not on the organization's contribution to society (e.g., producing a particular type of windows or doors). As a result, communication in these units, will tend to be 'function-related,' not 'flow' - and 'telos-related' (Seddon 2008; Donaldson 2001; Mintzberg 1983). It appears that high functional concentration stands in the way of realizing the three requirements. 


\section{Virtuous Unit Grouping: A Practical Example}

The Dutch homecare organization 'Buurtzorg' (Dutch for 'neighborhood care'), may be used to illustrate the effects of high and low functional concentration at the enterprise level on realizing the three requirements for virtuous behavior. Because of its success, (see Nandram (2015b, pp. 345-346) for Buurtzorg's successful performance in terms of quality of care and quality of work), Buurtzorg has been the object of recent (international) attention (cf. Monsen and de Blok 2013; Verloop and Hillen 2014; Nandram 2015a, b; and the Royal College of Nursing 2015).

Jos de Blok, the founder of Buurtzorg, a home-care nurse himself, was dissatisfied (in fact: morally indignant) with the functionally concentrated, hierarchical, and bureaucratic home-care organizations that were prevalent in the Netherlands since the 1980s. As an alternative, he set up an organization in which, "nurses form self-directed teams that provide home care services with minimal administrative oversight and in collaboration with patients, their families, physicians, and the community" (Monsen and de Blok 2013, p. 55).

The goal of Buurtzorg is to care, "for patients in need of home, hospice, and dementia care, working with the family, primary care providers, and community resources to help patients maintain their independence in the least restrictive environment possible" (Monsen and de Blok 2013, p. 55; de Blok 2011). To this purpose, Buurtzorg provides six key services: (1) holistic assessment of the client's needs, (2) mapping the client's networks of possible informal care, (3) indentifying and coordinating other formal care providers, (4) care delivery, (5) client support in his/her social environment, and (6) promotion of selfcare and independence (Royal College of Nursing 2015, pp. 3-4).

In the 'old' functionally concentrated homecare organizations, including the organization de Blok worked for, nurses were allocated to units performing one particular activity for all clients of the organization. Such a functionally concentrated homecare organization consists, for instance, of four units: a unit 'intake,' a unit 'house cleaning,' a unit 'personal hygiene,' and a unit 'personal health.' Caregivers in each of these units are potentially coupled to all the organization's clients and perform one of these four activities.

Apart from (possible) planning problems with respect to the allocation of caregivers to clients and (potentially) inefficient travel of caregivers between clients, this high functional concentration has two consequences that hinder the realization of the 'teleological,' 'social,' and 'deliberative' context required for exercising and developing moral character.

The first consequence of high functional concentration is that caregivers are potentially coupled to all clients. Because of this, each caregiver sees many different clients and each client sees many different caregivers. Monsen and de Blok (2013, p. 57) report the case of a client that was visited by more than 30 different caregivers in one month. As a result, it becomes hard, if not impossible, for caregivers and clients to develop meaningful human relations. Instead of caring for 'their' clients; i.e., clients that they know and are engaged with, caregivers care for clients that are seen as more or less abstract, exchangeable, 'objects' receiving care. And instead of being cared for by 'their' caregivers; i.e., caregivers that they know and are engaged with, clients see caregivers as more or less abstract, exchangeable, 'subjects' providing care.

The second consequence of high functional concentration in the 'old' homecare organizations is that each caregiver only performs a small part of the total process of providing homecare, e.g., a caregiver performs only 'cleaning' or only 'washing' activities. This makes it difficult, if not impossible, for caregivers to oversee the whole process of providing care and to become interested in both the effects of and their contribution to this process. Instead, caregivers concentrate on their own activity in this whole process, resulting in fragmented care (Nandram 2015a, p. 19).

Abstract relations between 'objects' and 'subjects' of care in contrast to meaningful human relations between client and caregiver and partial care in contrast to holistic care seem to be two consequences of functional differentiation.

In combination, these two consequences considerably reduce the probability of realizing the 'teleological,' 'social,' and 'deliberative' context requirements.

The teleological context requires organizational members to be in touch with the actual realization of the organization's goal; contributing to the quality of life and autonomy of clients. However, because of functional concentration, it is difficult for caregivers to both establish meaningful relations with individual clients and to see and assess the effects of their activities in the light of the 'telos' of the organization. Instead of providing 'holistic' care for 'their' clients, caregivers focus on performing their 'partial' activity with respect to continuously changing-more or less anonymous-clients (e.g., cleaning some client's house in a particular amount of time). As a result, they will run the risk of disengaging from the goal of the organization as a whole.

Moreover, because high functional concentration stands in the way of realizing the teleological context 
requirement, it also hinders effective communication about the organization's 'telos' which is a part of the social context requirement (requirement 3).

Finally, high functional concentration makes it difficult to both oversee and be interested in the (possible) moral consequences of one's actions. Because each caregiver directly moves to some next client ' $\mathrm{B}$ ' after, for instance, washing a client ' $\mathrm{A}$,' he or she is not in a position to experience the medical or house cleaning implications of the washing activity. Here, functional concentration, makes it impossible to oversee the moral (and other) consequences of one's actions. Moreover, because each caregiver sees many different clients and sees these clients only from the partial perspective of his or her activity, it also becomes difficult to become interested in the possible consequences of these actions. In this way, high functional concentration also stands in the way of realizing the deliberative context requirement. Because, both the ultimate goal of one's activities in a functionally structured organization remain hidden, it becomes difficult in this type of organization to choose the right action for the right reason. Moreover, because it is virtually impossible to oversee and be interested in the moral implications of one's actions, it becomes difficult to reflect on and learn from these implications in the light of the goal of these actions. However, both are necessary to exercise and develop workrelated virtues.

Because it is hard to realize the 'teleological,' 'social,' and 'deliberative' context requirement in a functionally concentrated structure, organizational members working in such a structure are not helped, but hindered to develop a work-related virtuous character. More in particular, organizational members are hindered to:

- keep in touch with and reflect on the goal of the organization in the light of doing the right thing for the right reasons (teleological context requirement);

- discuss their actions and reasons for doing them with relevant other organizational members in the light of doing the right thing for the right reasons, thereby establishing an organizational ethos (social context requirement);

- relate their own actions to the realization of the organizational goal and reflect on the appropriateness of these action in the light of doing what is the right thing, thereby exercising and developing their moral character (deliberative context requirement).

As such, functional concentration, seems a first step towards eradicating instead of fostering the exercise and development of our moral character in organizations.

In contrast, Buurtzorg has been organized to achieve a low level of functional concentration at the enterprise level. To this purpose, de Blok formed teams consisting of up to twelve nurses that perform all nursing activities for clients in a specific neighborhood (Monsen and de Blok 2013, p. 56; Nandram 2015a, 66-67). In this way, units are structured to couple caregivers to only a subset of the total client population, i.e., to 'their' clients in a particular neighborhood.

Besides advantages related to both the planning of the allocation of caregivers to clients and traveling time between clients, this functionally de-concentrated structure allows caregivers to stay in touch with the organization's goal, for caregivers in each team are related to the wellbeing and autonomy of 'their' more or less fixed set of clients in 'their' neighborhood (teleological context). More in particular, caregivers are given the opportunity to get to know their clients and to see the effects of their activities on both the quality of life and autonomy of these clients (teleological context). For instance, after changing to Buurtzorg, the client that saw 30 different caregivers per month, only sees one of three nurses (from a team of twelve) who, "bathes, toilets, and dresses him in addition to providing medications and preparing simple meals. Visits (two to three per day) last $30 \mathrm{~min}$ to an hour and demonstrate the bond he's formed with this nursing team" (Monsen and de Blok 2013, p. 57). In this way, nurses get the opportunity to reflect on the goal of the organization and its realization in actu from the perspective of doing the right thing for the right reasons.

In addition, caregivers are given the opportunity to discuss their activities both in relation to each other and their client's well-being, allowing them to fine-tune both their job-related skills and moral virtues (social context requirement).

Moreover, because caregivers can oversee and experience the consequences of their actions, they are enabled to exercise and develop their moral character. They can actually see the technical and moral implications of their actions, reflect on these implications, and in this way, develop their work-related moral virtues and practical wisdom.

Finally, low functional concentration at the enterprise level provides the right conditions for both decentralization and the design of virtuous jobs at the job level of the organization.

In general, from a virtue ethical perspective, low functional concentration at the enterprise level seems to be preferable to high functional concentration. It provides the required teleological and social context to organizational members and sets the stage for the design of jobs that enable organizational members to exercise and develop their moral character. High functional concentration, on the other hand, seems to stand in the way of the realization of the teleological and social context requirement. Moreover, once functional concentration is 'high,' it is virtually 
impossible to 'reintroduce' the required teleological and social context by means of the design of individual jobs.

\section{Enterprise Level: Decentralization}

\section{The Parameter Decentralization}

The second structural parameter that is relevant at the enterprise level is the degree of decentralization of decision authority; also referred to as the degree of participation in decision making (cf. Pugh et al. 1968; Aiken and Hage 1971; Pierce and Delbecq 1977). De Sitter (1994) defines decentralization in terms of the degree of separation between production and control activities.

In the case of 'low' decentralization, production and control activities are separated into different tasks. Decision authority is taken away from the operational level and concentrated in a hierarchy of managerial tasks. In case of 'high' decentralization, control and production activities are integrated into tasks. Decision authority is dispersed among (many) members of the organization-down to the operational level (cf. Zammuto and O'Connor 1992).

If decentralization is 'high,' organizational members can control their own production activities. Decentralized structures imply a flat hierarchy. In this paper, the parameter 'decentralization' is relevant for description and design purposes at the enterprise level of an organization. The parameter 'job specialization' deals with the allocation of regulatory (and operational) activities to jobs of individual members of the organization.

\section{Virtuous Decentralization and Its Application in Practice}

Once activities have been grouped into flows (low functional concentration), the level of decentralization directly affects the realization of the teleological and social context (requirements 1 and 3 ) and sets the stage for the deliberative context (requirement 2). It can be argued that high levels of decentralization in flow-oriented units have a positive effect on realizing these requirements.

High decentralization in flow-oriented units means that each unit is authorized to make decisions with respect to its own input, throughput and output and can participate in discussions about the strategy of the organization as a whole. The authority of each unit is governed by Beer's principle of freedom and constraint (Beer 1994). This principle entails that, under the constraint that it does not harm the viability of the organization as a whole, each unit has the freedom to make decisions about flow-related goals (strategic regulation), organizational design (regulation by design), and operational matters (operational regulation). By means of high decentralization, each of the units is not only focused on producing its contribution to society, governed by the principle of freedom and constraint, it can also regulate with respect to this contribution. Units can assume actual responsibility for both their own and the organization's contribution to society (teleological and social requirement).

In the case of Buurtzorg, decentralization is high. At the unit (i.c. team) level it is realized, roughly along Beer's principle of freedom and constraint. To begin with, decision power is allocated to the teams, making them 'selfdirected.' In this way, each team can, “develop its own 'personality' functioning as a unified whole [...] The nurses decide together what to do, and each team is recognized for its collective wisdom and knowledge of what is best for its patients and community" (Monsen and de Blok 2013, p. 57). 'Management' is needed only, "to keep (1) the outside world outside, particularly if it's disturbing the work of the nurses, and (2) the collective ambition and organizational principles alive" (ibid, p. 57). As a result, each team becomes responsible for shaping and realizing Buurtzorg's 'telos' in its own neighborhood (teleological requirement). Moreover, conditions are created for discussing this 'neighborhood'-related 'telos' in the team (social requirement).

Low decentralization in flow oriented units is detrimental to the realization of the teleological and social context requirement. Although units are focused on producing their particular contribution to society, they neither participate in strategic decision making about this contribution nor do they have the authority to decide with respect to their own input, throughput, and output. In this way, units get little or no responsibility for the goals they are supposed to realize or for the means they are supposed to use to realize these goals.

For a designer who wants to design virtuous structures, low decentralization in highly functionally concentrated units is a horrific scenario. Not only are these units primarily focused on their own function and not on the production of a particular subset of the organization's order types, they also are not involved in strategy formulation and have little say in the actual design and operational regulation of the unit. Now, it becomes almost impossible to be in touch with or involved in discussions about the organization's contribution to society (requirements 1 and 3). Actually, high functional concentration in combination with low decentralization was the case in the 'old' homecare organizations in the Netherlands. In these organizations, caregivers did not have decision power with respect to the regulation of their work. Instead, a hierarchy of managers was needed, sapping away scarce financial resources, and perhaps more important, the involvement, creativity, and professional love of the caregivers that did the actual work. In these organizations, caregivers became 'morally disengaged' from the work they were doing or, as 
in the case of de Blok, left the organization they worked for.

\section{Virtuous Structures at the Job Level}

In discussions about the relation between organizational structures and virtue ethics, the level of individual jobs gets the most attention (e.g., Weaver 2006; Beadle and Knight 2012). However, focusing on this level in isolation is dangerous. Without the right structural conditions at the enterprise level, it is difficult to establish the required relation between the 'telos' of the organization and the jobs of organizational members. Once high functional concentration and low decentralization at the enterprise level 'hide' the 'telos' of the organization to workers in the functionally concentrated units and 'rob' them of the decision power to regulate with respect to the processes and goals they pursue. It becomes hard, if not impossible, to 'reintroduce' both the 'telos' and the decision power at the level of individual jobs.

Given this proviso, it can be asked how individual job should be designed in order to enable the realization of the requirements connected to the development and application of work-related virtues.

At the job level, the relevant parameters are 'job specialization' and 'formalization.' The values of these parameters directly affect the possibilities organizational members have to exercise and develop their moral character in an adequate social context (requirements 2 and 3 ). If the right conditions have been created by means of unit grouping and decentralization at the enterprise level, the exercise of these virtues can be, as much as possible, related to the societal contribution and impact of the organization (requirement 1). Below, we first discuss the parameters job specialization and formalization ("Parameters at the Job Level: Jobs Specialization and Formalization" section). Then, we argue that low levels of job specialization and formalization are conducive to realizing the three context requirements ("Virtuous Structures at the Job Level" section). Finally, we illustrate this using the Buurtzorg example ("Virtuous Structures at the Job Level: Practical Example" section).

\section{Parameters at the Job Level: Jobs Specialization and Formalization}

As indicated, the parameter 'job specialization' refers to the design of individual jobs. It refers to the degree to which production or regulatory activities are split up into sub-tasks (cf. Pugh et al. 1968; Mintzberg 1983; de Sitter 1994; de Sitter and den Hertog 1997; Donaldson 2001). Organizations may vary on this parameter ranging from 'high' to 'low' specialization.
In the case of 'high' job specialization, the organization has many short-cycled, specialized operational jobs (high horizontal specialization) and many specialized regulatory jobs (vertical specialization). In the case of 'low' specialization, operational and regulatory activities are integrated into 'broad and coherent' jobs, covering a larger part of the operational process.

The parameter 'formalization' can be defined as the degree to which jobs must follow specified rules or procedures (e.g., Donaldson 2001, p. 22). In organizations with a high degree of formalization "[...] a codified body of rules, procedures or behavior descriptions is developed to handle decision and work processing" (Pierce and Delbecq 1977, p. 31). Moreover, as these authors add, such organizations see to "strict enforcement" of these rules and procedures. In organizations with low formalization, this type of procedural control is less important. Although formalization is a relevant parameter at both organizational levels, for our purposes in this paper, it is particularly important at the job level.

In organization design literature, high specialization is often accompanied by high formalization (as in bureaucracies) and low specialization is often treated along with low formalization (as in organic structures)—cf. Burns and Stalker 1961; Donaldson 2001. However, it should be stressed that they are separate parameters. It is possible to have a highly specialized job with low formalization-a small specific job with few rules or procedures governing it (e.g., your job is to put on safety stockings as part of elderly home care but you can do it as you see fit). Similarly, it is possible to have a broad job (in terms of covering a large part of the primary process) which is tightly governed by rules and procedures.

\section{Virtuous Structures at the Job Level}

\section{Virtuous Job Specialization}

Virtuous structures at the enterprise level are the point of departure for the design of virtuous jobs. This means that organizational members work in flows that allow them to be in touch with the organization's contribution to society. To these members, the units they work in appear as 'teams.' As a result of decentralization, these teams are semi-autonomous units (Thompson 1967; de Sitter 1993; Galbraith 1977; Anand and Daft 2007).

In order to enable team members to exercise and develop their moral character, jobs should be designed to: (1) allow them to see the consequences of their actions and (2) provide them with the operational variety and regulatory capacity needed to devise, choose and implement morally appropriate actions (i.e., requirement 2 should be met). 
To create a deliberative context, it seems advisable to keep the value of the parameter job specialization low. This means that team members have relatively long cycled, broad and logically cohesive operational tasks. These tasks should comprise activities that, as much as possible, reflect the organization's contribution to society. Moreover, operational tasks should be designed to (partially) overlap. This allows team members to help each other. Finally, team members should have the authority to regulate with respect to both their own and the team's effort. More in particular, they should be allowed to cope with work-related problems (operational regulation), to contribute to design issues (e.g., the design of working methods; design regulation), and to the team's strategy formulation (strategic regulation).

Because of the design of their jobs, team members remain, as much as is possible, in touch with the organization's contribution to society and can see the impact of their activities on the organization's end products or clients. Broad and partially overlapping tasks allow organizational members to actually make a difference to the work of others and both see and discuss what this difference is. This effect is amplified by introducing regulatory activities into the tasks of team members. Team members are induced to feel responsible for and discuss regulatory decisions, can experience the effects of these decisions on their own and the team's functioning, and can see what these decisions mean for their clients. In this way, both the team and the individual job become a 'locus' for the exercise and development of work-related skills, moral virtues and practical wisdom.

These, from a virtue ethical perspective, beneficial effects, are hard to realize in the worst case situation of high job specialization in a highly functionally concentrated enterprise level structure. Such a design systematically severs the connection between organizational members and their organization's contribution to society. Moreover, because jobs are devoid of operational and regulatory variety, they reduce opportunities organizational members have to feel involved with and responsible for their actions.

\section{Virtuous Formalization}

It is easy to see that high formalization would 'undo' the benefits of the operational and regulatory variety of virtuous jobs. The operational variety that is given to team members is taken away by a codified body of rules, procedures, or behavior descriptions developed to handle decision and work processing. Moreover, regulatory variety is reduced by 'regulators' enforcing these rules and procedures. For this reason, in virtuous structures, low jobs specialization should be accompanied by low formalization. Given the principle of freedom and constraint, low formalization allows organizational members to discuss and develop job-related values, norms, and standards based on their work experiences (see also Schwartz and Sharpe 2010 for the influence of formalization). Formalization, then, disables a deliberative context.

\section{Virtuous Structures at the Job Level: Practical Example}

In the example of Buurtzorg, individual jobs are designed to keep both job specialization and formalization low. In the team, each caregiver performs the six activities that constitute Buurtzorg's core activities mentioned above. In contrast to the short cycle times in the case of high job specialization (e.g., quickly washing a client to move on to the next one), caregivers are allowed relatively long cycle times to perform the activities they consider necessary (even up to an hour as Monsen and de Blok (2013, p. 57) report). This allows caregivers to see, assess and improve the impact and meaning of their work. Moreover, caregivers, as a part of their job, coordinate and regulate with respect to the team's effort. This not only reduces coordination costs, it also allows caregivers to help each other if this is needed. Low specialization combined with low formalization, provides caregivers with the freedom to assess, on a day to day basis, their clients well-being and to act on this assessment. In this way, they can develop their 'ethos' with respect to both their work and their organization's contribution to society.

In the worst case example of high job specialization and high formalization in a functionally concentrated and centralized home care organization, caregivers are subjected to a regime of small and short-cycled tasks governed by highly specified standards. For instance, a 'housecleaner' should perform a prescribed set of activities in a particular amount of time and then move on to a next client according to a schedule produced by the planning department. Moreover, because of vertical specialization, caregivers have no say in what the activities, the standards, or the schedule should be. Not only does this type of organization prohibit the realization of the teleological context criterion (who is still interested in the well-being and autonomy of one of many clients?), it also hinders caregivers: to see the impact of their actions and enjoy the operational and regulatory variety needed to exercise their moral character, and to communicate about both their own work and the organization's contribution to society. In fact, the detrimental 'moral' effects of high job specialization and high formalization echo the moral problems of bureaucracies raised by others (e.g., Merton 1957; MacIntyre 1985; Jos 1988; Luban et al. 1992). 


\section{Virtuous Structures and Networks}

Although the topic of this paper is virtuous structures in organizations, some attention should be paid to inter-organizational networks taken as "a variety of forms of cooperation, including joint ventures, strategic alliances, collaborations, and consortia" (Provan et al. 2007, p. 481). The reason for this is that, for instance, an organization may be structured to comply with the three requirements defined above. But what if this organization has concentrated on designing clothes and sources the finished product from sweatshops in a country far away (cf. Anand and Daft 2007 on 'hollow organizations')? Or, an organization may participate in a network of organizations that provides a particular product or service (cf. Anand and Daft 2007 on 'modular organizations'). But, what if this network is structured in a way that does not provide conditions for the development and application of work-related virtues?

To start discussing this difficult topic, it is useful to distinguish between at least two questions. The first question pertains to the selection of network partners, the second to the structural design of the network.

With regard to the first question (selection), it can be argued that all organizations need to deal with this question. The reason for this is that all organizations in some way depend on other organizations, e.g., for (raw) materials, equipment, capital, or services. These inter-organizational dependency relations also imply that some organizations source other organizations with products or services. In this way, a complex and dynamic matrix of sourcing relations is established. Given its primary activities each organization in this matrix has its own network of in- and/or output dependency relations with other organizations (cf. Thompson 1967 on domains of organized action and task environments; see also Borgatti and Foster 2003).

Contingent on market characteristics, organizations are more or less free to select the organizations they engage with or to define the terms of this engagement. For instance, an organization requiring a particular input that is offered by many organizations and demanded by many (other) organizations, enjoys more degrees of freedom than an organization requiring input that is offered by only a few and demanded by many organizations (Thompson 1967; Scott 2003).

However, in spite of these differing degrees of freedom, it is, perhaps, still possible to suggest a principle of "virtuous" selection (for a discussion of similar principles related to labor conditions and social issues in supply chains, see Ciliberti et al. 2009). For in- and output purposes, an organization in focus that wants to enable the application and development of work-related virtues, should:

1. as much as is possible, engage with organizations that also have this goal and the accompanying virtuous structures and in- and/or output relations to show for it;

2. as much as is needed, encourage organizations it engages with to pursue this goal and to implement the accompanying virtuous structures and in- and output relations;

3. abstain from engaging with organizations that continuously, explicitly, and deliberately violate the realization of this goal, for instance, by means of the products or services they deliver, the design of their structure, or their in- and output relations with other organizations.

If this principle is applied, the organization in focus preferably engages with organizations that, in turn, preferably engage with organizations that want to enable the application and development of work-related virtues. In this way, this organization, ideally, becomes part of a network of organizations, that apply this principle: a virtuous network of inter-organizational in- and output relations.

The second question pertains to the structural design of networks: how should a network's structure be designed to enable the development and application of work-related virtues? This question is particularly relevant for organizations that engage in a more or less durable cooperation with other organizations to produce products or services for particular groups of clients, each of the participating organizations, in isolation, could not have produced (cf. Anand and Daft 2007 on modular organizations). In such cases, not only selection is an issue, but also the network's structural design.

An example might be a network designed to provide integrated care for problematic youngsters in a city. In the Netherlands, such networks were established under the name of the 'Veiligheidshuis' (literally, the 'Safety House'). In a Veiligheidshuis, local schools, the police force, the public prosecutor, clinics for psychiatric and addiction care, institutions supporting community work, and local employers work together to improve the well being and societal prospects of these youngsters. Each of the organizations participating in this network has its own goals and primary activities, its own organizational structure, and is involved in its own network of in- and/or output relations. Moreover, each of these organizations, in isolation, can provide a thread of the safety needed by the targeted youngsters in that city. However, in isolation, the primary activities of the participating organizations do not provide the actual integration of these threads into an 
effective safety net. To actually weave this net, (1) the network's goal should be formulated, e.g., 'providing integrated care for problematic youngsters,' (2) organizations participating in the network should be selected (using the selection principle specified above), and (3) the network should be structured to enable not only the realization of the formulated goal, but also the requirements for the exercise and development of work-related virtues.

Just as in the case of the macro-level of organizations, the structural parameters 'unit grouping' and 'decentralization' seem to be the most important parameters at the level of the network (Provan et al. 2007, p. 485 deal with decentralization in terms of 'governance'). By means of the values of these parameters, the network should be structured to provide the required teleological and a social context and set the stage for individual jobs that allow organizational members to exercise their moral character.

An extreme case of functionally concentration and centralization, may serve as our point of departure. In this case, each of the participating organizations, by means of its own primary activities, personnel, and equipment, provides its own contribution to the network's output. Like the 'sawing,' 'sanding,' 'assembly' and 'finishing' departments in a functionally concentrated organization, each of the organizations participating in the network focuses on its own functional contribution with respect to all order types. In order to realize the network's goal (e.g., the integrated care for youngsters), the participating organizations need to coordinate the integration of their contributions. This integration can be achieved by means of 'standardization' in the case of pooled dependency relations between the contributions of the participating organizations and the network's final output, 'planning' in the case of sequential dependency relations, and 'mutual adjustment' in the case of reciprocal dependency relations (cf. Thompson 1967 or Mintzberg 1983). In the example of the Veiligheidshuis, coordination was achieved by a team consisting of representatives of the participating organizations, discussing youngsters on a case by case basis (mutual adjustment). Based on these discussions, the required effort of each of the participating organizations was determined and fed back to these organizations. High centralization in this case means that the participating organizations have little say in both the network's strategy and design.

From the perspective of virtue ethics, such a functionally concentrated network seems suboptimal. Workers in each of the participating organization primarily focus on the 'telos' of their own organization. The only way to stay in touch with the network's goal is by means of the coordination mechanism, in the case of the Veiligheidshuis, the team discussing the youngsters case by case. Low decentralization, further reduces chances to feel involved with or communicate about the network's goal. In the case of the
Veiligheidshuis, regulation with respect to goals-i.e., balancing between the network's goal and the goals of the participating organizations-proved to be quite cumbersome.

At the other extreme, a design supporting flow production and decentralization may be implemented. To this purpose, the participating organizations establish a new unit (e.g., a joint venture) in which the operational activities needed to realize the network's goal are grouped. This unit has its 'own' goal (e.g., improving the well-being and societal prospects of difficult youngsters), activities, personnel (that may be seconded by the participating organizations), and equipment. This unit may, then, be subdivided into further flows. Moreover, the unit performs its own regulatory activities. Given the principle of freedom and constraint, it can decide with regard to its own strategy, design, and operational regulation. In this way, conditions are created for workers in the new unit to keep in touch with the network's goal and to discuss the unit's contribution to and impact on society (teleological and social requirement). Just as in the case of the enterprise level of individual organizations, the realization of the teleological and social context requirement at the level of inter-organizational networks seem to be related to flow production and high decentralization.

In sum, although it is impossible here to exhaustively discuss the topic of 'responsible networks,' it can still be argued that the effects of intra-organizational structures enabling organizational members to exercise their moral character are not necessarily 'undone' at the network level. Careful selection of network partners and prudent design of network structures, in principle, can help organizational members to live a fulfilled life in the organizations and networks they work for.

\section{Conclusion}

In this paper, we discussed organizational structures enhancing the exercise and development of moral character- 'virtuous' structures. To discuss them, we considered what it means to 'exercise and develop one's moral character' in the context of doing one's job (i.e., it entails genuinely desiring that the organizational output contributes to the well-being of organizational and societal members, and deliberating, choosing and implementing job-related actions realizing this desire). Moreover, we argued that in order for organizational members to exercise and develop their moral character, three requirements (a "teleological," "deliberative" and "social" context) should be realized. Next, referring to four structural parameters and two organizational levels, we described the type of structures that can help realize these requirements. 
These structures, ideally, consist of 'rich' jobs within semiautonomous teams within larger semi-autonomous flows (in the case of Buurtzorg, the teams even equaled the flows). Low functional concentration, resulting in flow production and semi-autonomous teams at the enterprise level are needed to allow organizational members to stay in touch with and communicate about the 'telos' of the organization (teleological and social context condition) and enable the design of rich jobs at the micro-level. Rich jobs, i.e., low levels of specialization, separation and formalization at the job level, are needed to allow organizational members to see the consequences of their activities, to give them the operational and regulatory variety needed to exercise and develop their moral character, and to discuss their activities with each other (deliberative and social context requirement).

In addition, we explored the type of structures of organizational networks conducive to virtuous behavior. Here, we described criteria for the selection of virtuous network partners and discussed that if networks of organizations are functionally concentrated and centralized, they risk the chance of disabling the exercise and development of moral character. Creating partnerships of teams of network-partners who jointly work on complete processes and are jointly responsible for realizing some output seems to be more desirable.

In our paper, we indicated that several authors have already discussed the enhancing role of structures for exercising and developing moral character. With this paper, we contributed to this discussion in the following ways. First, our framework contains more structural parameters than appear in the extant literature. In particular, as we have argued, "unit grouping" is an important but neglected parameter. Second, we extend the extant literature by providing a more detailed framework for understanding and designing the required structures for virtuousness. We hope that our analysis makes more explicit that and how structural parameters are involved in designing tasks in which one can be in touch with goals and output and in which one has the operational and regulatory variety needed for exercising and developing virtues. This framework thus enables us to appreciate the complex of parameters involved in suggestions for structural improvements made in prior literature. Third, we extend current thinking about structures for exercising virtues by discussing the interrelations between and the joint effect of structural parameters on virtuous behavior. We discussed, for instance, that structures at the macro-level condition the design of individual jobs in which virtues can be exercised and developed. We also discussed that the positive effect of one parameter on virtuousness can be enhanced or frustrated by the effect of another parameter (e.g., that high formalization may undo the positive effect of low job- specialization). Fourth, the framework adds to our understanding of supportive structures by including three different levels: the macro-level of the organization, the micro-level of individual work, and the level of networks of organizations. In the extant literature, the network level is hardly touched upon.

In closing this paper, we would like to remark that delineating "virtuous structures" is only a part of the bigger project of delineating "virtuous organizations." Structures are not the only supportive organizational elements. Besides the presence of virtuous structures, other organizational factors may still influence the behavior of organizational members. For instance, appraisal and reward systems (cf. Schwartz and Sharpe 2010; Schwartz 2011), culture (e.g., the work on "ethical climates" starting with Victor and Cullen 1988); or particular styles of leadership (e.g., Treviño et al. 2000) may either undo or help realize the opportunities created by virtuous structures. The same holds for technologies supporting organizational processes. For instance, technologies increasing or the physical and emotional distance between organizational members and clients may harm virtuous behavior (cf. Jones 1991, on the relation between 'distance' and virtuous behavior). An important line of research, then, might be to align this knowledge and to arrive at supportive infrastructures (comprising for instance supportive structures, culture, leadership, technology, or incentive-systems) so as to understand how organizations may foster exercising and developing moral character of its members.

Open Access This article is distributed under the terms of the Creative Commons Attribution 4.0 International License (http://crea tivecommons.org/licenses/by/4.0/), which permits unrestricted use, distribution, and reproduction in any medium, provided you give appropriate credit to the original author(s) and the source, provide a link to the Creative Commons license, and indicate if changes were made.

\section{References}

Achterbergh, J., \& Vriens, D. (2010). Organizations: Social systems conducting experiments. New York: Springer.

Aiken, M., \& Hage, J. (1971). The organic organization and innovation. Sociology, 5, 63-81.

Anand, N., \& Daft, R. L. (2007). What is the right organization design? Organizational Dynamics, 36(4), 329-344.

Aristotle. (1984). Ethica Nicomachea. In J. Barnes (Ed.), The complete works of Aristotle (revised edition):1729-1867. Princeton: Princeton University Press.

Bauman, Z. (1989). Modernity and the Holocaust. Ithaca, NY: Cornell University Press.

Beabout, G. R. (2012). Management as a domain relative practice that requires and develops practical wisdom. Business Ethics Quarterly, 22(2), 405-432.

Beadle, R., \& Knight, K. (2012). Virtue and meaningful work. Business Ethics Quarterly, 22(2), 433-450. 
Beer, S. (1994). The heart of enterprise. Chicester: Wiley.

Bernacchio, C., \& Couch, R. (2015). The virtue of participatory governance: a MacIntyrean alternative to stakeholder maximization. Business Ethics: A European Review, 24(S2), 130-143.

Bertland, A. (2009). Virtue ethics in business and the capabilities approach. Journal of Business Ethics, 84, 25-32.

Borgatti, S. P., \& Foster, P. C. (2003). The network paradigm in organizational research: A review and typology. Journal of Management, 29(6), 991-1013.

Breen, K. (2007). Work and emancipatory practice: Towards a recovery of human beings' productive capacities. Res Republica, 13, 381-414.

Breen, K. (2012). Production and productive reason. New Political Economy, 17(5), 611-632.

Burns, T., \& Stalker, G. M. (1961). The management of innovation. Oxford: Oxford University Press.

Ciliberti, F., de Groot, G., de Haan, J., \& Pontrandolfo, P. (2009). Codes to coordinate supply chains: SMEs' experiences with SA8000. Supply Chain Management: an International Journal, 14(2), 117-127.

Collins, D. (1987). Aristotle and business. Journal of Business Ethics, $6,567-572$.

de Blok, J. (2011). Buurtzorg Nederland: A new perspective on elderly care in the Netherlands. The Journal/AARP International, 2011(summer), 82-86.

de Sitter, U. L. (1994). Synergetisch produceren. Assen: van Gorkum.

de Sitter, U. L., \& den Hertog, J. F. (1997). From complex organizations with simple jobs to simple organizations with complex jobs. Human Relations, 50(5), 497-534.

Donaldson, L. (2001). The contingency theory of organizations. London: Sage.

Galbraith, J. R. (1977). Organization design. London: AddisonWesley.

Grant, A. M. (2007). Relational job design and the motivation to make a prosocial difference. Academy of Management Review, 32(2), 393-417.

Hartman, E. M. (2008). Reconciliation in business ethics: some advice from Aristotle. Business Ethics Quarterly, 18, 253-265.

Jones, T. M. (1991). Ethical decision making by individuals in organizations: an issue-contingent model. Academy of Management Review, 16(2), 366-385.

Jos, P. H. (1988). Moral autonomy and the modern organization. Polity, 21(2), 321-343.

Koehn, D. (1998). Virtue ethics, the firm, and moral psychology. Business Ethics Quarterly, 8(3), 497-513.

Kolb, D. A. (1984). Experiential learning: Experience as the source of learning and development. Englewood cliffs, NJ: Prentice Hall.

Luban, D., Strudler, A., \& Wasserman, D. (1992). Moral responsibility in the age of bureaucracy. Michigan Law Review, 90(8), 2348-2392.

MacIntyre, A. (1985). After virtue (2nd ed.). London: Duckworth.

MacIntyre, A. (1999). Social structures and their threat to moral agency. Philosophy, 3, 311-329.

Merton, R. K. (1957). Social theory and social structure. New York: Free Press.

Michaelson, C. (2011). Whose responsibility is meaningful work? Journal of Management Development, 30(6), 548-557.

Michaelson, C., Pratt, M. G., Grant, A. M., \& Dunn, C. P. (2014). Meaningful work: Connecting business ethics and organization studies. Journal of Business Ethics, 121, 77-90.

Mintz, S. M. (1996). Aristotelian virtue and business education. Journal of Business Ethics, 15, 827-838.

Mintzberg, H. (1983). Structures in fives. Englewood Cliffs, NJ: Prentice-Hall.
Monsen, K., \& de Blok, J. (2013). Buurtzorg Nederland. A nurse-led model of care has revolutionized home care in the Netherlands. American Journal of Nursing, 113(8), 55-59.

Moore, G. (2005a). Humanizing business: A modern virtue ethics approach. Business Ethics Quarterly, 15(2), 237-255.

Moore, G. (2005b). Corporate character: Modern virtue ethics and the virtuous corporation. Business Ethics Quarterly, 15(4), 659-685.

Moore, G. (2008). Re-imagining the morality of management: A modern virtue ethics approach. Business Ethics Quarterly, 18(4), $483-511$.

Moore, G. (2012). The virtue of governance, the governance of virtue. Business Ethics Quarterly, 22(2), 293-318.

Moore, G., \& Beadle, R. (2006). In search of organizational virtue in business: Agents, goods, practices, institutions and environments. Organization Studies, 27(3), 369-389.

Nadler, D. A., \& Tushman, M. L. (1997). Competing by design. New York: Oxford University Press.

Nandram, S. (2015a). Organizational innovation by integrating simplification. Learning from Buurtzorg Nederland. Heidelberg: Springer.

Nandram, S. (2015b). 'Buurtzorg': A Case of Being-Centredness as Example of an Organic Worldview for Corporate Peace. Business, Ethics and Practice. Published online: 21 Sep 2015: 333-349.

Newton, L. (1992). Virtue and role: Reflections on the social nature of morality. Business Ethics Quarterly, 2, 357-365.

Nussbaum, M. C. (2011). Creating capabilities: The human development approach. Harvard: Harvard University Press.

Nussbaum, M. C., \& Sen, A. (Eds.). (1993). The quality of life. Oxford: Oxford University Press.

Pierce, J. L., \& Delbecq, A. L. (1977). Organization structure, individual attitudes and innovation. Academy of Management Review, 2(1), 27-37.

Provan, K. G., Fish, A., \& Sydow, J. (2007). Interorganizational networks at the network level. A review of the empirical literature on whole networks. Journal of Management, 33(3), 479-516.

Pugh, D. S., Hickson, D. J., Hinings, C. R., \& Turner, C. (1968). Dimensions of organization structure. Administrative Science Quarterly, 13(1), 65-105.

Royal College of Nursing. (2015). The Buurtzorg Nederland (home care provider) model. Observations for the United Kingdom. RCN Policy and International Department Policy Briefing, 02(15), 1-11.

Schwartz, A. (1982). Meaningful work. Ethics, 92(4), 634-646.

Schwartz, B. (2011). Practical wisdom in organizations. Research in Organizational Behavior, 31, 3-23.

Schwartz, B., \& Sharpe, K. (2010). Practical wisdom. New York: Riverhead Books.

Scott, W. R. (2003). Organizations: Rational, natural and open systems. Upper Saddle River, NJ: Prentice Hall.

Seddon, J. (2008). Systems thinking in the public sector. Axminster: Triarchy Press.

Sherman, N. (1989). The fabric of character: Aristotle's theory of virtue. Oxford: Oxford University Press.

Sison, A. J. G., \& Fontrodona, J. (2012). The common good of the firm in the Aristotelian-Thomistic tradition. Business Ethics Quarterly, 22(2), 211-246.

Solomon, R. C. (1992). Corporate roles, personal virtues. Business Ethics Quarterly, 2(3), 317-339.

Solomon, R. C. (2003). Victims of circumstances? A defense of virtue ethics in business. Business Ethics Quarterly, 13(1), 43-62.

Solomon, R. C. (2004). Aristotle, ethics and business organizations. Organization Studies, 25(6), 1021-1043. 
Thompson, J. D. (1967). Organizations in action. New York: McGraw-Hill.

Treviño, L. K., Hartman, L. P., \& Brown, M. E. (2000). Moral person and moral manager. California Management Review, 42, 128-142.

van Tongeren, P. (2004). Een deugdelijk leven. Nijmegen: Sun uitgeverij.

Verloop, W., \& Hillen, M. (2014). Social enterprise unraveled. Best practices from the Netherlands. Amsterdam: Warden Press.

Victor, B., \& Cullen, J. B. (1988). The organizational bases of ethical work climates. Administrative Science Quarterly, 33, 101-125.

Walker, A. H., \& Lorsh, J. W. (1968). Organizational choice: Product vs. function. Harvard Business Review, 46, 129-138.
Walsh, A. J. (1994). Meaningful work as a distributive good. Southern Journal of Philosophy, 32(2), 233-250.

Weaver, G. R. (2006). Virtue in organizations: Moral identity as a foundation for moral agency. Organization Studies, 27(3), 341-368.

Womack, J. P., Jones, D. T., \& Roos, D. (1990). The Machine that changed the world. New York: Rawson Associates.

Zammuto, R. F., \& O'Connor, E. (1992). Gaining advanced manufacturing technologies' benefits: the role of organization design and culture. Academy of Management Review, 17(4), 701-728. 